\title{
Differential Inhibition of Neuronal and Extraneuronal Monoamine Oxidase
}

\author{
Graeme Eisenhofer, Ph.D., Jacques W. M. Lenders, M.D., Ph.D., Judith Harvey-White, B.S., \\ Monique Ernst, M.D., Ph.D., Alan Zametkin, M.D., Dennis L. Murphy, M.D., \\ and Irwin J. Kopin, M.D.
}

This study examined whether the newronal and extraneuronal sites of action of two monoamine oxidase (MAO) inhibitors, l-deprenyl and debrisoquin, could be distinguishet by their effects on plasma concentrations of catecholamine metabolites. Plasma concentrations of the intraneuronal deaminated metabolite of norepinephrine, dilydroxyphenylglycol (DHPG), were decreased by $77 \%$ after debrisoquin and by $64 \%$ after l-deprenyl administration. Plasma concentrations of the extraneuronal O-methylated metabolite of norepineplinine, normetanephrine, were increased substantially more during treatment aith

KEY WORDS: Monoamine oxidase; Monoamine oxidase inhibitors; Catecholamines; Metabolism; Norepineplirine; Normetanephrine

The monoamine oxidases (MAO) A and B catalyze the deamination of biogenic amines and represent targets for therapeutic intervention in several neuropsychiatric conditions (Murphy et al. 1980; Berry et al. 1994b). Abnormal MAO activity has been implicated in alcoholism, depression, and other psychiatric disorders (Gershon et al. 1979; Devor et al. 1993), but the discovery of

From the Clinical Neuroscience Branch, National Institute of Neurological Disorders and Stroke (CE, JH-W, JJK), Child Psychiatry Branch (ME, AZ), and Laboratory of Clinical Science (DLM), National Institute of Mental Health, National Institutes of Health, Bethesda, Maryland; and Department of Medicine (JWML), Division of General Internal Medicine, St. Radboud University Hospital, Nijmegen, The Netherlands.

Address correspondence to: Graeme Eisenhofer, Ph.D., Building 10, Room 5N214, National Institutes of Health, 10 Center Drive, MSC 1+2t, Bethesda, MD 20892-1424.

Received August 17, 1995; revised October 17, 1995; accepted October 18,1995 l-deprenyl than with debrisoquin (255\% compared to a $27 \%$ increase). The comparable decreases in plasma concentrations of DHPG indicate a similar inhibition of intraneuronal MAO by both drugs. Much larger increases in normetanephrine after l-deprenyl than after debrisoquin are consistent with a site of action of the latter drug directed at the neuronal rather than the extraneuronal compartment. Thus, differential changes in deaminated and O-methylated amine metabolites allows identification of neuronal and extraneuronal sites of action of MAO inhibitors.

[Neuropsychopharmacology 15:296-301, 1996]

a family with an X-linked point mutation of the MAO-A gene where afflicted males exhibit impaired impulse control provides the most compelling evidence for a role of MAO in the expression of behavior (Brunner et al. 1993).

Recognizing that MAO is differentially distributed among and within tissues and cell types (Berry et al. 1994a; Lai et al. 1994; Thorpe et al. 1987) raises the possibility that involvement of the enzyme in different neuropsychiatric conditions might depend on regional abnormalities in MAO activity. Targeting therapeutic interventions to specific tissues or cell types would therefore provide a means for tailoring treatment to the specific neuropsychiatric condition.

This study examined whether differences in MAO activity among neuronal and extraneuronal compartments can be distinguished using plasma concentrations of catecholamine metabolites. Dihydroxyphenylglycol (DHPG), produced largely by deamination of norepinephrine within sympathetic neurons (Goldstein et al. 1988) provided an index of intraneuronal MAO ac- 
tivity. Normetanephrine and metanephrine, O-methylated metabolites of norepinephrine and epinephrine and substrates for extraneuronal MAO, were indices of extraneuronal MAO activity. Other measurements of the catecholamine precursor, dihydroxyphenylalanine (DOPA), and of the dopamine metabolite, dihydroxyphenylacetic acid (DOPAC), provided indices of tyrosine hyd roxylase activity and dopamine deamination. Intraneuronal MAO was inhibited with debrisoquin, a drug that is concentrated in sympathetic nerves by neuronal uptake (Giachetti and Shore 1967; Medina et al. 1969; Pettinger et al. 1969). The effects of debrisoquin were compared with those of l-deprenyl, administered at a dose sufficient to cause inhibition of both MAO-A and MAO-B.

\section{METHODS}

\section{Subjects}

The study population included 26 healthy volunteers (mean \pm SD, age $45 \pm 24$ years) and 14 patients with attention-deficit hyperactivity disorder (mean $\pm \mathrm{SD}$, age $36 \pm 7$ years). Subjects included 34 males and 6 females. Women of childbearing potential were excluded. Experimental protocols were approved by the intramural review boards of the two institutes involved in the study and subjects gave written informed consent to participate.

\section{Procedures}

Debrisoquin was obtained as a gift from Hoffman-La Roche (Nutley, $\mathrm{NJ}$ ) and formulated for administration as tablets in the National Institutes of Health pharmacy. The drug was administered to 26 normal volunteers at graded doses over a 9-day inpatient stay at the Clinical Center, National Institutes of Health. During the first 3 days, subjects were administered placebo tablets. On the fourth and fifth days, subjects were administered 10 $\mathrm{mg}$ of debrisoquin daily. The dose was increased to 20 $\mathrm{mg}$ a day over the next 2 days and to $40 \mathrm{mg}$ a day during the last 2 days. Total daily doses were divided into four equal doses delivered 6 hours apart. Blood samples $(10 \mathrm{ml})$ were collected by venipuncture from a forearm vein with subjects in the supine position. The data presented here represent results for samples drawn on the third and the last day on which subjects received debrisoquin.

L-deprenyl (Selegiline hydrochloride, Eldepryl) was provided by Somerset Pharmaceuticals Inc (Tampa, FL). The drug was administered orally to 14 subjects at a dose of $60 \mathrm{mg}$ per day for 6 weeks, a dose previously established to cause inhibition of both MAO-A and MAO-B (Sunderland et al. 1985). Subjects received l-deprenyl on an outpatient basis but returned to the clinical center for periodic clinical evaluation, including sampling of blood.
Blood samples $(10 \mathrm{ml})$ were collected by venipuncture from a forearm vein with subjects in the semi-supine position. The data presented here represent results for samples drawn before and during the last week during which subjects received l-deprenyl.

\section{Processing of Blood Samples}

Blood samples were transferred into tubes containing heparin or EDTA and centrifuged to separate the plasma. The plasma was removed and stored at $-80^{\circ} \mathrm{C}$ until assayed for concentrations of catechols and metabolites. Plasma concentrations of norepinephrine, epinephrine, DHPG, DOPA, and DOPAC were estimated by liquid chromatography with electrochemical detection after alumina extraction (Eisenhofer et al. 1986). Plasma concentrations of normetanephrine and metanephrine were also estimated using liquid chromatography with electrochemical detection following extraction on solid-phase ion-exchange columns (Lenders et al. 1993). Plasma concentrations of sulfate-conjugated normetanephrine and metanephrine were estimated similarly after incubation of $200-\mu 1$ samples of plasma with sulfatase (Sigma Chemical Co., St Louis, MO) at $37^{\circ} \mathrm{C}$ for 30 minutes.

\section{Statistical Methods}

Differences in plasma concentrations of catecholamines, DOPA, and metabolites before and during treatment with MAO inhibitors were assessed using the Student's paired $t$-test. Differences in changes in concentrations during treatment with 1-deprenyl versus debrisoquin were assessed by two-way analysis of variance (ANOVA). Because of the nature of the within-subjects study design, variances in changes in concentrations before and during MAO inhibitor treatment are shown using standard errors of the differences.

\section{RESULTS}

Plasma concentrations of norepinephrine were decreased by $20 \%$ to $26 \%$ during treatment with debrisoquin $(p<.001)$ or l-deprenyl $(p<.05)$, whereas plasma concentrations of epinephrine were unaffected (Table 1). Plasma concentrations of the catecholamine precursor DOPA were decreased by $47 \%$ during treatment with debrisoquin $(p<.001)$ and by $21 \%$ with l-deprenyl $(p<.002)$. Plasma concentrations of the deaminated dopamine metabolite DOPAC were decreased similarly by $53 \%$ to $55 \%$ during treatment with debrisoquin $(p<$ $.001)$ or l-deprenyl $(p<.001)$, whereas concentrations of DHPG, the deaminated metabolite of norepinephrine and epinephrine, were decreased by $77 \%$ with debrisoquin $(p<.001)$ and by $63 \%$ with 1 -deprenyl $(p<.001)$. 
Table 1. Plasma Concentrations of Catecholamines, DOPA, and Catecholamine Metabolites before and during

Treatment with Debrisoquin or L-deprenyl

\begin{tabular}{|c|c|c|c|c|}
\hline & $n$ & Baseline & Treatment & SED \\
\hline \multicolumn{5}{|l|}{ Norepinephrine } \\
\hline Debrisoquin & 20 & 1.10 & 0.81 & $0.08^{*}$ \\
\hline L-deprenyl & 14 & 2.52 & 2.01 & $0.22^{*}$ \\
\hline \multicolumn{5}{|l|}{ Epinephrine } \\
\hline Debrisoquin & 10 & 0.10 & 0.09 & 0.02 \\
\hline L-deprenyl & 12 & 0.39 & 0.33 & 0.05 \\
\hline \multicolumn{5}{|l|}{ DOPA } \\
\hline Debrisoquin & 19 & 7.04 & 4.36 & $0.26^{*}$ \\
\hline L-deprenyl & 14 & 8.22 & 6.45 & $0.63^{*}$ \\
\hline \multicolumn{5}{|l|}{ DOPAC } \\
\hline Debrisoquin & 20 & 7.68 & 3.04 & $0.56^{*}$ \\
\hline L-deprenyl & 14 & 10.32 & 4.69 & $1.32^{*}$ \\
\hline \multicolumn{5}{|l|}{ DHPG } \\
\hline Debrisoquin & 20 & 4.28 & 0.97 & $0.28^{*}$ \\
\hline L-deprenyl & 14 & 5.82 & 1.89 & $0.12^{*}$ \\
\hline \multicolumn{5}{|c|}{ Normetanephrine } \\
\hline Debrisoquin & 16 & 0.32 & 0.35 & $0.03+$ \\
\hline L-deprenyl & 13 & 0.29 & 0.91 & $0.21+$ \\
\hline \multicolumn{5}{|l|}{ Metanephrine } \\
\hline Debrisoquin & 16 & 0.14 & 0.17 & $0.01+$ \\
\hline L-depreny] & 14 & 0.14 & 0.18 & $0.01+$ \\
\hline \multicolumn{5}{|c|}{ Normetanephrine-sulfate } \\
\hline Debrisoquin & 15 & 7.35 & 13.76 & $0.52 \dagger$ \\
\hline L-deprenyl & 13 & 7.61 & 25.28 & $2.79+$ \\
\hline \multicolumn{5}{|c|}{ Metanephrinte-sulfate } \\
\hline Debrisoquin & 15 & 3.17 & 4.42 & $0.37 \dagger$ \\
\hline L-deprenyl & 14 & +.02 & 9.81 & $3.24 t$ \\
\hline
\end{tabular}

Results are mean concentrations (nmol/L) with variance among paired data show'n by standard errors of the difference (SED). $n=$ number of observations. *denotes a decrease $(p-05)$, whereas tdenote's an increase $(p<.05)$ during treatment

MAO-inhibition-induced decreases in plasma concentrations of deaminated metabolites contrasted with increases $(z<.05)$ in the O-methylated metabolites, normetanephrine, and metanephrine (Table 1). Decreases in deaminated metabolites did not differ significantly during treatment with 1-deprenyl and debrisoquin, whereas there were strikingly smaller increases in plasma concentrations of normetanephrine $(F=19.2, \mu<$ $.001)$ and normetanephrine sulfate $(F=11.3, p<.005)$ during treatment with debrisoquin than with 1-deprenyl (Figure 1). During treatment with 1-deprenyl plasma concentrations of free normetanephrine increased by $255 \%$, whereas with debrisoquin, there was only a $27 \%$ increase. Similarly, normetanephrine sulfate increased by $260 \%$ after 1 -deprenyl, but only by $100 \%$ after debrisoquin. Debrisoquin caused larger $(\beta<.001)$ increases in sulfate-conjugated than -unconjugated normetanephrine.

The MAO-inhibition-induced increases in plasma metanephrine were smaller $\left(<25^{\circ} \circ\right.$ increases) than those for normetanephrine and did not differ during treatment with 1-deprenyl or debrisoquin (Figure 1). In-
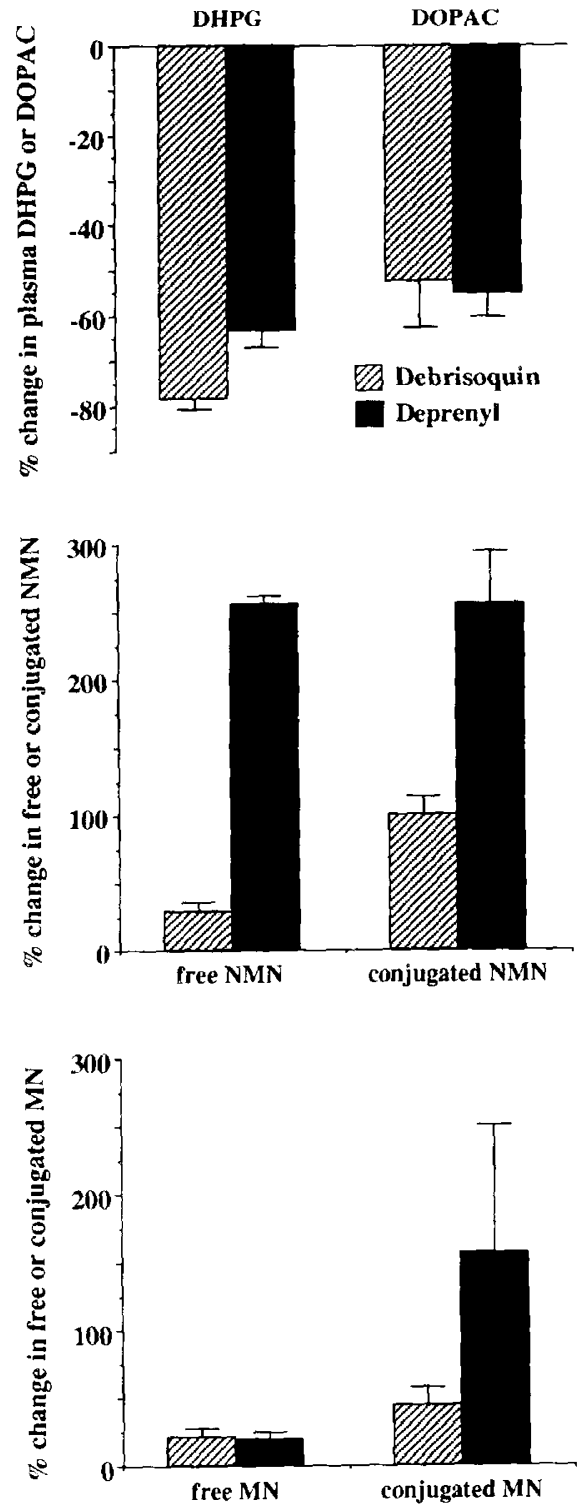

Figure 1. Percentage changes in plasma concentrations of DHPG and DOPA (fop) and plasma concentrations of free and sulfate conjugated normetanephrine (middle) and of metanephrine (bottom) during treatment with debrisoquin (dingonal bars) or deprenyl (solid bars).

creases in sulfate-conjugated metanephrine tended to be larger after MAO inhibition than those in unconjugated metanephrine and larger with l-deprenyl than with debrisoquin.

\section{DISCUSSION}

Considering how MAO is compartmentalized among and within tissues provides a basis for understanding how regional abnormalities in MAO activity may be involved in specific neuropsychiatric disorders and how 
targeting particular cell types may offer a useful approach for therapeutic intervention. The differential changes in deaminated and O-methylated catecholamine metabolites after 1-deprenyl and debrisoquin administration illustrate how measurements of biogenic amine metabolites can be used to distinguish the activity of MAO in different cellular compartments.

DHPG in plasma is predominantly produced by the deamination of norepinephrine within sympathetic nerves (Goldstein et al. 1988). Thus, the large decreases in plasma DHPG after debrisoquin and l-deprenyl indicate that both drugs are effective inhibitors of intraneuronal MAO. In contrast, normetanephrine and metanephrine are produced by extraneuronal O-methylation of norepinephrine and epinephrine (Graefe and Henseling 1983). Thus, MAO-inhibition-induced increases in plasma normetanephrine and metanephrine result from inhibition of their deamination in extraneuronal compartments. MAO-inhibition-induced increases in plasma normetanephrine and metanephrine are also secondary to the resulting increased availability of precursor catecholamines for O-methylation.

The large $250 \%$ increase in plasma concentrations of free normetanephrine after deprenyl is similar in magnitude to MAO-inhibition-induced increases in plasma normetanephrine in rats (Eisenhofer and Finberg 1994) or increases in urinary excretion of normetanephrine in humans (Linnoila et al. 1982; Koulu et al. 1989; Berlin et al. 1990). The increase is also consistent with the sereral-fold higher than normal plasma concentrations of normetanephrine in patients with X-linked deletion of the genes for MAO-A and B (Eisenhofer et al. 1995).

The minimal increases in plasma normetanephrine after debrisoquin agree with previous findings of little change in the urinary excretion of normetanephrine after 6 to 8 weeks of treatment with debrisoquin (Silas et al. 1979). Much smaller increases in plasma normetanephrine after debrisoquin than after 1-deprenyl-despite a similar magnitude of inhibition of intraneuronal MAO by both drugs - indicate less effective inhibition of extraneuronal $\mathrm{MAO}$ after debrisoquin than after l-deprenyl administration. The selectivity of debrisoquin for inhibition of neuronal over extraneuronal MAO is consistent with the primary intraneuronal actions of the drug that result from its active uptake and concentration by sympathetic nerves (Giachetti and Shore 1967; Medina et al. 1969; Pettinger et al. 1969). The results show that differences in MAO activity among neuronal and extraneuronal compartments may be distinguished by comparisons of plasma concentrations of the intraneuronal deaminated metabolite of norepinephrine DHPG with those of the extraneuronal metabolite normetanephrine.

At low doses (5-10 mg/day in humans), 1-deprenyl, is a more selective inhibitor of MAO-B than of MAO-A. Thus, previous findings in canine saphenous vein that normetanephrine is deaminated by MAO-B (Caramona and Osswald 1985) could also explain the differential effects of the two drugs. However, other findings in rats that plasma normetanephrine is increased by selective inhibition of $\mathrm{MAO}-\mathrm{A}$, but not of $\mathrm{MAO}-\mathrm{B}$, indicate that normetanephrine is not a substrate for the latter isoenzyme (Eisenhofer and Finberg 1994). The selectivity of MAO-A for deamination of normetanephrine has been confirmed in humans by findings that specific genetic deficiencies of $\mathrm{MAO}-\mathrm{B}$ do not result in increased plasma concentrations of normetanephrine, whereas deficiencies of MAO-A cause similar increases to those found in patients with deficiencies of both isoenzymes (Lenders et al. 1996).

Smaller increases in plasma concentrations of metanephrine than of normetanephrine after inhibition of $\mathrm{MAO}$ are consistent with findings in rats where inhibition of MAO-A caused fourfold increases in normetanephrine and only twofold increases in metanephrine (Eisenhofer and Finberg 1994). In addition, patients with X-linked deletion of the genes for MAO-A and B show smaller increases above normal in plasma metanephrine than in normetanephrine (Eisenhofer et al. 1995). Smaller MAO-inhibition-induced increases in plasma metanephrine than normetanephrine are explained by differences in their sites of formation. Over $90 \%$ of plasma metanephrine is derived from metabolism of epinephrine within the adrenal gland where O-methylation, not deamination, is the primary pathway of metabolism (Eisenhofer et al. 1995). Although significant amounts of normetanephrine are also produced within the adrenals, most is formed in extraneuronal and extraadrenal tissues from norepinephrine released by sympathetic nerves.

Small, but significant, decreases in plasma norepinephrine after administration of both MAO inhibitors suggest decreases in norepinephrine release, as a result of either decreased sympathetic outflow or of replacement of norepinephrine by octopamine. The sympatholytic effects of debrisoquin are well established and provided the basis for the initial introduction of the drug as an antihypertensive (Giachetti and Shore 1967). A similar action of 1-deprenyl is not established, but is consistent with findings of sympathoinhibitory actions of other MAO inhibitors (Lavian et al. 1994). The study design, where there were differences in duration of drug treatment and no controls for temporal influences or possible changes in plasma catecholamine clearance precludes definitive interpretation of the changes in plasma norepinephrine. These factors and differences in subject groups (i.e., outpatients versus hospitalized normal volunteers) or posture at time of blood sampling may also account for differences in baseline variables; however, they are unlikely to be responsible for the differential changes in plasma concentrations of O-methylated and deaminated metabolites during treatment with the two MAO inhibitors. 
The decreases in plasma DOPA after MAO inhibition are consistent with previous findings (Eisenhofer et al. 1986, 1988), where these changes reflect feedback inhibition of tyrosine hydroxylase by increased axoplasmic concentrations of norepinephrine. Because MAO-A is the predominant form of the enzyme in sympathetic neurons, the decrease in plasma DOPA indicates that both drugs inhibit the enzyme. This finding is also consistent with lowered plasma concentrations of DOPA in patients with X-linked deficiencies of MAO-A, but not in those with absent MAO-B (Lenders et al. 1996).

Divergent changes in plasma concentrations of O-methylated and deaminated catecholamine metabolites provide a sensitive approach to detect generalized disorders or drug-associated changes of biogenic amine metabolism. The results also illustrate how differential changes in these metabolites may be useful for detecting tissue- or cell-specific differences in the deamination of biogenic amines.

\section{REFERENCES}

Berlin I, Zimmer R, Thiede H-M, Payan C, Hergueta I, Robin L, Puech AJ (1990): Comparison of the monoamine oxidase inhibiting properties of two selective monoamine oxidase- $\mathrm{A}$ inhibitors moclobemide and toloxatone, and assessment of their effects on psychometric performance in healthy subjects. Br J Clin Pharmacol 30:805816

Berry MD, Juorio AV, Paterson IA (1994a): The functional role of monoamine oxidases $\mathrm{A}$ and $\mathrm{B}$ in the mammalian central nervous system. Prog Neurobiol 42:375-391

Berry MD, Juorio AV, Paterson IA (1994b): Possible mechanisms of action of (-)deprenyl and other MAO-B inhibitors in some neurologic and psychiatric disorders. Prog Neurobiol 44:141-161

Brunner HG, Nelen MR, van Zandvoort P, Abeling NGGM, ran Gennip AH, Wolters EC, Kuiper MA, Ropers HH, van Oost BA (1993): X-linked borderline mental retardation with prominent behavioural disturbance: Phenotype, genetic localization, and evidence for disturbed monoamine metabolism. Am J Hum Genet 52:10321039 .

Caramona MM, Osswald W (1985): Effects of clorgyline and (-)-deprenyl on the deamination of normetanephrine and noradrenaline in strips and homogenates of the canine saphenous vein. Jaunvn-Schmiedeberg's Arch Pharmacol 328:396-400

Devor EJ, Cloninger CR, Hoffman PL, Tabakoff B (1993): Association of monoamine oxidase (MAO) activity with alcoholism and alcoholic subtypes. Am J Med Genet 48:209-213

Eisenhofer G, Finberg JPM (1994): Different metabolism of norepinephrine and epinephrine by catechol-O-methyltransferase and monoamine oxidase in rats. J Pharmacol Exp Ther 268:1242-1251

Eisenhofer G, Goldstein DS, Stull R, Keiser HR, Sunderland T, Murphy DL, Kopin IJ (1986): Simultaneous liquid- chromatographic determination of 3,4-dihydroxy-phenylglycol, catecholamines, and 3,4-dihydroxyphenylalanine in plasma, and their responses to inhibition of monoamine oxidase. Clin Chem 32:2030-2033

Eisenhofer G, Goldstein DS, Ropchak TG, Kopin IJ (1988) Source and physiological significance of plasma 3,4dihydroxyphenylalanine in the rat. J Neurochem 51: 1204-1213

Eisenhofer G, Friberg P, Pacak K, Goldstein DS, Murphy DL, Tsigos C, Quyyumi AA, Brunner HG, Lender JWM (1995): Plasma metadrenalines: Do they provide useful information about sympatho-adrenal function and catecholamine metabolism. Clin Sci 88:533-542

Gershon ES, Targun SD, Leckman JF (1979): Platelet monoamine oxidase (MAO) activity and genetic vulnerability to bipolar (BP) affective illness. Psychopharmacol Bull 15:27-30

Giachetti A, Shore PA (1967): Monoamine oxidase inhibition in the adrenergic neuron by bretylium, debrisoquin, and other adrenergic blocking agents. Biochem Pharmacol $16: 237-238$

Goldstein DS, Eisenhofer G, Stull R, Folio CJ, Keiser HR, Kopin IJ (1988): Plasma dihydroxyphenylglycol and the intraneuronal disposition of norepinephrine in humans. J Clin Invest 81:213-220

Graefe K-H, Henseling M (1983): Neuronal and extraneuronal uptake and metabolism of catecholamines. Gen Pharmacol 14:27-33

Koulu M, Scheinin M, Kaarttinen A, Kallio J, Pyykkö K, Vuorinen J, Zimmer RH (1989): Inhibition of monoamine oxidase by moclobemide: Effects on monoamine metabolism and secretion of anterior pituitary hormones and cortisol in healthy volunteers. Br J Pharmacol 27:243255

Lai JCK, Leung TKC, Lim L (1994): Heterogeneity of monoamine oxidase activities in synaptic and non-synaptic mitochondria derived from three brain regions: Some functional implications. Metab Brain Dis 9:53-66

Lavian G, Finberg JP, Youdim MB (1994): Comparison of the effect of reversible and irreversible $\mathrm{MAO}$ inhibitors on renal nerve activity in the anesthetized rat. J Neural Transm 41:107-113

Lenders JWM, Eisenhofer G, Armando I, Keiser HR, Goldstein DS, Kopin IJ (1993): Determination of metanephrines in plasma by liquid chromatography with electrochemical detection. Clin Chem 39:97-103

Lenders JWM, Eisenhofer G, Abeling NGGM, Berger W, Murphy DL, Konings $\mathrm{H}$, Bleeker Wagemakers LM, Kopin IJ, Karoum F, van Gennip AH, Brunner HG (1996): Specific genetic deficiencies of the $A$ and $B$ isoenzymes of monoamine oxidase are characterized by distinct neurochemical and clinical phenotypes. J Clin Invest (in press)

Linnoila M, Karoum F, Potter WZ (1982): Effect of low lowdose clorgyline on 24-hour urinary monoamine excretion in patients with rapidly cycling bipolar affective disorder. Arch Gen Psychiatry 39:513-516

Medina MA, Giachetti A, Shore PA (1969): On the physiological disposition and possible mechanism of the antihypertensive action of debrisoquin. Biochem Pharmacol 18:891-901 
Murphy DL, Garrick NA, Cohen RM (1980): Monoamine oxidase inhibitors and monoamine oxidase: Biochemical and physiological aspects relevant to human psychopharmacology. In Burrow's GD, Norman TR, Davies B (eds), Antidepressants. Amsterdam, Elsevier, pp. 209227

Pettinger WA, Korn A, Spiegel H, Pocelinko R, Abrams WB (1969): Debrisoquin, a selective inhibitor of intraneuronal monoamine oxidase in man. J Pharmacol Ther $10: 667-674$

Silas JH, Jones J, Tucker GT, Townshend MM, Phillips CA,
Smith AJ (1979): Dissociation of biochemical and hypotensive effects of debrisoquine in hypertensive patients. Eur J Clin Pharmacol 16:81-86

Sunderland T, Mueller EA, Cohen RM, Jimerson DC, Pickar D, Murphy DL (1985): Tyramine precursor sensitivity changes during deprenyl treatment. Psychopharmacology 86:432-437

Thorpe LW, Westlund KN, Kochersperger LM, Abell CW, Denney RM (1987): Immunocytochemical localization of monoamine oxidases $\mathrm{A}$ and $\mathrm{B}$ in human peripheral tissues and brain. J Histochem Cytochem 35:23-32 